\title{
A New Hybrid Algorithm for $\lambda$-Strict Asymptotically Pseudocontractions in 2-Uniformly Smooth Banach Spaces
}

\author{
Xin-dong Liu ${ }^{1}$ and Shih-sen Chang ${ }^{2}$ \\ ${ }^{1}$ Department of Mathematics, Yibin University, Yibin, Sichuan 644007, China \\ ${ }^{2}$ College of Statistics and Mathematics, Yunnan University of Finance and Economics, \\ Kunming, Yunnan 650221, China \\ Correspondence should be addressed to Shih-sen Chang, changss@yahoo.cn
}

Received 29 June 2012; Accepted 27 August 2012

Academic Editor: RuDong Chen

Copyright (c) 2012 X.-d. Liu and S.-s. Chang. This is an open access article distributed under the Creative Commons Attribution License, which permits unrestricted use, distribution, and reproduction in any medium, provided the original work is properly cited.

\begin{abstract}
A new hybrid projection algorithm is considered for a $\lambda$-strict asymptotically pseudocontractive mapping. Using the metric projection, a strong convergence theorem is obtained in a uniformly convex and 2-uniformly smooth Banach spaces. The result presented in this paper mainly improves and extends the corresponding results of Matsushita and Takahashi (2008), Dehghan (2011) Kang and Wang (2011), and many others.
\end{abstract}

\section{Introduction}

Let $E$ be a real Banach space and $E^{*}$ be the dual spaces of $E$. Assume that $J$ is the normalized duality mapping from $E$ into $2^{E^{*}}$ defined by

$$
J(x)=\left\{x^{*} \in E^{*}:\left\langle x, x^{*}\right\rangle=\|x\|^{2}=\left\|x^{*}\right\|^{2}\right\}, \quad \forall x \in E,
$$

where $\langle\cdot, \cdot\rangle$ is the generalized duality pairing between $E$ and $E^{*}$.

Let $C$ be a nonempty closed convex subset of a real Banach space $E$.

Definition 1.1. Let $T: C \rightarrow C$ be a mapping:

(1) $T$ is said to be nonexpansive if for all $x, y \in C$,

$$
\|T x-T y\| \leq\|x-y\|,
$$


(2) $T$ is said to be asymptotically nonexpansive if there exists a sequence $\left\{k_{n}\right\} \subset[1, \infty)$ with $k_{n} \rightarrow 1$ such that for all $x, y \in C$,

$$
\|T x-T y\| \leq k_{n}\|x-y\|,
$$

(3) $T$ is said to be $\lambda$-strictly pseudocontractive in the terminology of BrowderPetryshyn [1] if there exists a constant $\lambda \in(0,1)$ such that for all $x, y \in C$,

$$
\langle T x-T y, j(x-y)\rangle \leq\|x-y\|^{2}-\lambda\|(I-T) x-(I-T) y\|^{2}, \quad \forall j(x-y) \in J(x-y),
$$

(4) $T$ is said to be $\left(\lambda,\left\{k_{n}\right\}\right)$-strict asymptotically pseudocontractive if there exist a constant $\lambda \in(0,1)$ and a sequence $\left\{k_{n}\right\} \subset[1, \infty)$ with $k_{n} \rightarrow 1$ such that for all $x, y \in C$ and for all $j(x-y) \in J(x-y)$,

$$
\left\langle T^{n} x-T^{n} y, j(x-y)\right\rangle \leq k_{n}\|x-y\|^{2}-\lambda\left\|\left(I-T^{n}\right) x-\left(I-T^{n}\right) y\right\|^{2}, \quad \forall n \geq 1,
$$

(5) $T$ is said to be uniformly $L$-Lipschitzian if there exists a constant $L>0$ such that

$$
\left\|T^{n} x-T^{n} y\right\| \leq L\|x-y\|, \quad \forall n \geq 1 .
$$

It is wellknown that the class of $\left(\lambda,\left\{k_{n}\right\}\right)$-strictly asymptotically pseudocontractive mappings was first introduced in Hilbert spaces by Liu [2]. In the case of Hilbert spaces, it is shown by [2] that (1.5) is equivalent to the inequality

$$
\left\|T^{n} x-T^{n} y\right\|^{2} \leq k_{n}\|x-y\|^{2}+\lambda\left\|\left(I-T^{n}\right) x-\left(I-T^{n}\right) y\right\|^{2} .
$$

Concerning the convergence problem of iterative sequences for strictly pseudocontractive mappings has been studied by several authors (see [1,3-20]). Concerning the class of strictly asymptotically pseudocontractive mappings, Liu [2] proved the following results.

Theorem 1.2. Let $H$ be a real Hilbert space, let $C$ be a nonempty closed convex and bounded subset of $H$, and let $T: C \rightarrow C$ be a completely continuous uniformly L-Lipschitzian $\left(\lambda,\left\{k_{n}\right\}\right)$-strictly asymptotically pseudocontractive mapping such that $\sum_{n=1}^{\infty}\left(k_{n}^{2}-1\right)<\infty$. Let $\left\{\alpha_{n}\right\} \subset(0,1)$ be a sequence satisfying the following condition:

$$
0<\epsilon \leq \alpha_{n} \leq 1-\lambda-\epsilon, \quad \forall n \geq 1 \text { and some } \epsilon>0 .
$$

Then, the sequence $\left\{x_{n}\right\}$ generated from an arbitrary $x_{1} \in C$ by

$$
x_{n+1}=\left(1-\alpha_{n}\right) x_{n}+\alpha_{n} T^{n} x_{n}, \quad \forall n \geq 1
$$

converges strongly to a fixed point of $T$.

In 2007, Osilike et al. [21] proved the following theorem. 
Theorem 1.3. Let $E$ be a real q-uniformly smooth Banach space which is also uniformly convex, let $C$ be a nonempty closed convex subset of $E$, let $T: C \rightarrow C$ be a $\left(\lambda,\left\{k_{n}\right\}\right)$-strictly asymptotically pseudocontractive mapping such that $\sum_{n=1}^{\infty}\left(k_{n}^{2}-1\right)<\infty$, and let $F(T) \neq \emptyset$. Let $\left\{\alpha_{n}\right\} \subset(0,1)$ be a real sequence satisfying the following condition:

$$
0<a \leq \alpha_{n} \leq b<\frac{q(1-k)}{2 c_{q}}(1+L)^{-(q-2)}, \quad \forall n \geq 1 .
$$

Let $\left\{x_{n}\right\}$ be the sequence defined by (1.9). Then, $\left\{x_{n}\right\}$ converges weakly to a fixed point of T.

On the other hand, by using the metric projection, Nakajo and Takahashi [22] introduced the following iterative algorithms for the nonexpansive mapping $T$ in the framework of Hilbert spaces:

$$
\begin{gathered}
x_{0}=x \in C, \\
y_{n}=\alpha_{n} x_{\mathrm{n}}+\left(1-\alpha_{n}\right) T x_{n}, \\
C_{n}=\left\{z \in C:\left\|z-y_{n}\right\|\right\} \leq\left\|z-x_{n}\right\|, \\
Q_{n}=\left\{z \in C:\left\langle x_{n}-z, x-x_{n}\right\rangle \geq 0\right\}, \\
x_{n+1}=P_{C_{n} \cap Q_{n}} x, \quad n=0,1,2, \ldots,
\end{gathered}
$$

where $\left\{\alpha_{n}\right\} \subset[0, \alpha], \alpha \in[0,1)$ and $P_{C_{n} \cap Q_{n}}$ is the metric projection from a Hilbert space $H$ onto $C_{n} \cap Q_{n}$. They proved that $\left\{x_{n}\right\}$ generated by (1.11) converges strongly to a fixed point of $T$.

In 2006, Xu [23] extended Nakajo and Takahashi's theorem to Banach spaces by using the generalized projection.

In 2008, Matsushita and Takahashi [24] presented the following iterative algorithms for the nonexpansive mapping $T$ in the framework of Banach spaces:

$$
\begin{gathered}
x_{0}=x \in C, \\
C_{n}=\overline{\mathrm{co}}\left\{z \in C:\|z-T z\| \leq t_{n}\left\|x_{n}-T x_{n}\right\|\right\}, \\
D_{n}=\left\{z \in C:\left\langle x_{n}-z, J\left(x-x_{n}\right)\right\rangle \geq 0\right\}, \\
x_{n+1}=P_{C_{n} \cap D_{n}} x, \quad n=0,1,2, \ldots,
\end{gathered}
$$

where $\overline{\mathrm{co}} C$ denotes the convex closure of the set $C, J$ is normalized duality mapping, $\left\{t_{n}\right\}$ is a sequence in $(0,1)$ with $t_{n} \rightarrow 0$, and $P_{C_{n} \cap D_{n}}$ is the metric projection from $E$ onto $C_{n} \cap D_{n}$. Then, they proved that $\left\{x_{n}\right\}$ generated by (1.12) converges strongly to a fixed point of nonexpansive mapping $T$.

Recently, Dehghan [25] introduced the following hybrid projection algorithm for an asymptotically nonexpansive mapping $T$ in the framework of Banach spaces:

$$
\begin{gathered}
x_{0}=x \in C, \quad C_{0}=D_{0}=C, \\
C_{n}=\overline{\mathrm{co}}\left\{z \in C_{n-1}:\left\|z-T^{n} z\right\| \leq t_{n}\left\|x_{n}-T^{n} x_{n}\right\|\right\}, \\
D_{n}=\left\{z \in D_{n-1}:\left\langle x_{n}-z, J\left(x-x_{n}\right)\right\rangle \geq 0\right\}, \\
x_{n+1}=P_{C_{n} \cap D_{n}} x, \quad n=1,2, \ldots,
\end{gathered}
$$


where $\overline{\text { co }} C$ denotes the convex closure of the set $C,\left\{t_{n}\right\}$ is a sequence in $(0,1)$ with $t_{n} \rightarrow 0$, and $P_{C_{n} \cap D_{n}}$ is the metric projection from $E$ onto $C_{n} \cap D_{n}$. Then, he proved that $\left\{x_{n}\right\}$ generated by (1.13) converges strongly to a fixed point of an asymptotically nonexpansive mappings $T$. Motivated by the research work going on in this direction, the purpose of this paper is to introduce the following iteration for finding a fixed point of $\left(\lambda,\left\{k_{n}\right\}\right)$-strict asymptotically pseudocontraction in a uniformly convex and 2-uniformly smooth Banach spaces:

$$
\begin{gathered}
x_{0}=x \in C, \quad C_{0}=C, \\
C_{n}=\overline{\mathrm{co}}\left\{z \in C_{n-1}:\left\|z-T^{n} z\right\| \leq t_{n}\left\|x_{n}-T^{n} x_{n}\right\|\right\}, \\
x_{n+1}=P_{C_{n}} x, \quad n=1,2, \ldots,
\end{gathered}
$$

where $\overline{\text { CO }} C$ denotes the convex closure of the set $C,\left\{t_{n}\right\}$ is a sequence in $(0,1)$ with $t_{n} \rightarrow$ 0 , and $P_{C_{n}}$ is the metric projection from $E$ onto $C_{n}$. Under suitable conditions some strong convergence theorem for the sequence $\left\{x_{n}\right\}$ defined by (1.14) to converge a fixed point of an asymptotically $\lambda$-strictly pseudocontraction. The result presented in the paper extends and improves the main results of Matsushita and Takahashi [24], Dehghan [25], Kang and Wang [26], and others.

\section{Preliminaries}

In this section, we recall the well-known concepts and results which will be needed to prove our main results. Throughout this paper, we assume that $E$ is a real Banach space and $C$ is a nonempty subset of $E$. When $\left\{x_{n}\right\}$ is a sequence in $E$, we denote strong convergence of $\left\{x_{n}\right\}$ to $x \in E$ by $x_{n} \rightarrow x$ and weak convergence by $x_{n} \rightarrow x$.

A Banach space $E$ is said to be strictly convex if $\|x+y\| / 2<1$ for all $x, y \in U=\{z \in$ $E:\|z\|=1\}$ with $x \neq y$. E is said to be uniformly convex if for each $\epsilon>0$ there is a $\delta>0$ such that for $x, y \in E$ with $\|x\|,\|y\| \leq 1$ and $\|x-y\| \geq \epsilon,\|x+y\| \leq 2(1-\delta)$ holds. The modulus of convexity of $E$ is defined by

$$
\delta_{E}(\epsilon)=\inf \left\{1-\left\|\frac{x+y}{2}\right\|:\|x\|,\|y\| \leq 1,\|x-y\| \geq \epsilon\right\}
$$

$E$ is said to be smooth if the limit

$$
\lim _{t \rightarrow 0} \frac{\|x+t y\|-\|x\|}{t}
$$

exists for all $x, y \in U$. The modulus of smoothness of $E$ is defined by

$$
\rho_{E}(t)=\sup \left\{\frac{1}{2}(\|x+y\|+\|x-y\|)-1:\|x\| \leq 1,\|y\| \leq t\right\}
$$

A Banach space $E$ is said to be uniformly smooth if $\rho_{E}(t) / t \rightarrow 0$ as $t \rightarrow 0$. A Banach space $E$ is said to be q-uniformly smooth, if there exists a fixed constant $c>0$ such that $\rho_{E}(t) \leq c t^{q}$. 
If $E$ is a reflexive, strictly convex and smooth Banach space, then for any $x \in E$, there exists a unique point $x_{0} \in C$ such that

$$
\left\|x_{0}-x\right\|=\min _{y \in C}\|y-x\|
$$

The mapping $P_{C}: E \rightarrow C$ defined by $P_{C} x=x_{0}$ is called the metric projection from $E$ onto $C$. Let $x \in E$ and $u \in C$. Then it is known that $u=P_{C} x$ if and only if

$$
\langle u-y, J(x-u)\rangle \geq 0, \quad \forall y \in C
$$

For the details on the metric projection, refer to [27-30].

In the sequel, we make use of the following lemmas for our main results.

Lemma 2.1 (see [31]). Let $E$ be a real Banach space, $C$ a nonempty subset of $E$, and $T: C \rightarrow C$ a $\left(\lambda,\left\{k_{n}\right\}\right)$-strictly asymptotically pseudocontractive mapping. Then $T$ is uniformly L-Lipschitzian.

Lemma 2.2 (see [32]). Let E be a real 2-uniformly smooth Banach spaces with the best smooth constant $K$. Then the following inequality holds:

$$
\|x+y\|^{2} \leq\|x\|^{2}+2\langle y, J(x)\rangle+2\|K y\|^{2}
$$

for any $x, y \in E$.

Lemma 2.3 (demiclosed principle [21]). Let E be a real q-uniformly smooth Banach space which is also uniformly convex. Let $C$ be a nonempty closed convex subset of $E$ and $T: C \rightarrow C a\left(\lambda,\left\{k_{n}\right\}\right)$ strictly asymptotically pseudocontractive mapping with a nonempty fixed point set. Then $I-T$ is demiclosed at zero, where $I$ is the identical mapping.

Lemma 2.4 (see [33]). Let $C$ be a closed convex subset of a uniformly convex Banach space. Then for each $r>0$, there exists a strictly increasing convex continuous function $\gamma:[0, \infty) \rightarrow[0, \infty)$ such that $\gamma(0)=0$ and

$$
r\left(\left\|T\left(\sum_{j=0}^{m} \mu_{j} z_{j}\right)-\sum_{j=0}^{m} \mu_{j} T z_{j}\right\|\right) \leq \max _{0 \leq j<k \leq m}\left(\left\|z_{j}-z_{k}\right\|-\left\|T z_{j}-T z_{k}\right\|\right),
$$

for all $m \geq 1,\left\{\mu_{j}\right\}_{j=0}^{m} \in \Delta^{m},\left\{z_{j}\right\}_{j=0}^{m} \subset C \cap B_{r}$ and $T \in \operatorname{Lip}(C, 1)$, where $\Delta^{m}=\left\{\left\{\mu_{0}, \mu_{1}, \ldots, \mu_{m}\right\}\right.$ : $0 \leq \mu_{j}(0 \leq j \leq m)$ and $\left.\sum_{j=0}^{m} \mu_{j}=1\right\}, B_{r}=\{x \in E:\|x\| \leq r\}$ and $\operatorname{Lip}(C, 1)$ is the set of all nonexpansive mappings from $C$ into $E$.

\section{Main Results}

Now we are ready to give our main results in this paper. 
Lemma 3.1. Let $C$ be a nonempty subset of a real 2-uniformly smooth Banach space $E$ with the best smooth constant $K$, and $T: C \rightarrow C$ be $a\left(\lambda,\left\{k_{n}\right\}\right)$-strict asymptotically pseudocontraction. For $\alpha \in(0,1) \cap\left(0, \lambda / K^{2}\right]$, one defines

$$
S_{n, \alpha} x=\frac{1}{\sqrt{2 \alpha\left(k_{n}-1\right)+1}}\left[(1-\alpha) x+\alpha T^{n} x\right]
$$

for all $x \in C$ and each $n \geq 1$. Then $S_{n, \alpha}: C \rightarrow E$ is a nonexpansive.

Proof. For any $x, y \in C$, put $\beta_{n, \alpha}=\sqrt{2 \alpha\left(k_{n}-1\right)+1}$, we compute

$$
\begin{aligned}
& \left\|S_{n, \alpha} x-S_{n, \alpha} y\right\|^{2} \\
& =\left\|\frac{1}{\beta_{n, \alpha}}\left[(1-\alpha) x+\alpha T^{n} x\right]-\frac{1}{\beta_{n, \alpha}}\left[(1-\alpha) y+\alpha T^{n} y\right]\right\|^{2} \\
& =\frac{1}{\beta_{n, \alpha}^{2}}\left\|(x-y)+\alpha\left(T^{n} x-T^{n} y-(x-y)\right)\right\|^{2} \\
& \leq \frac{1}{\beta_{n, \alpha}^{2}}\left(\|x-y\|^{2}+2 \alpha\left\langle T^{n} x-T^{n} y-(x-y), j(x-y)\right\rangle\right. \\
& \left.\quad \quad+2 K^{2} \alpha^{2}\left\|T^{n} x-T^{n} y-(x-y)\right\|^{2}\right) \\
& =\frac{1}{\beta_{n, \alpha}^{2}}\left(\|x-y\|^{2}+2 \alpha\left\langle T^{n} x-T^{n} y, j(x-y)\right\rangle\right. \\
& \left.\quad \quad-2 \alpha\|x-y\|^{2}+2 K^{2} \alpha^{2}\left\|T^{n} x-T^{n} y-(x-y)\right\|^{2}\right) \\
& \leq \frac{1}{\beta_{n, \alpha}^{2}}\left(\|x-y\|^{2}+2 \alpha\left(k_{n}\|x-y\|^{2}-\lambda\left\|T^{n} x-T^{n} y-(x-y)\right\|^{2}\right)\right. \\
& \left.\quad \quad-2 \alpha\|x-y\|^{2}+2 K^{2} \alpha^{2}\left\|T^{n} x-T^{n} y-(x-y)\right\|^{2}\right) \\
& \quad \quad \frac{1}{\beta_{n, \alpha}^{2}}\left\{\left(1+2 \alpha k_{n}-2 \alpha\right)\|x-y\|^{2}-2 \alpha \lambda\left\|T^{n} x-T^{n} y-(x-y)\right\|^{2}\right. \\
& \quad\|x-y\|^{2}, \\
& \left.\quad+2 K^{2}\left\|T^{n} x-T^{n} y-(x-y)\right\|^{2}\right\}
\end{aligned}
$$

which shows that $S_{n, \alpha}$ is a nonexpansive mapping. This completes the proof.

Theorem 3.2. Let $C$ be a nonempty bounded and closed convex subset of a uniformly convex and 2-uniformly smooth Banach spaces $E$ with the best smooth constant $K>0$, assume that $T: C \rightarrow C$ 
is a $\left(\lambda,\left\{k_{n}\right\}\right)$-strict asymptotically pseudocontraction such that $\mathcal{F}=\mathscr{F}(T) \neq \emptyset$. Let $\left\{t_{n}\right\}$ be a sequence in $(0,1)$ with $t_{n} \rightarrow 0$. Let $\left\{x_{n}\right\}$ be a sequence generated by $(1.14)$, where

$$
\overline{\mathrm{CO}}\left\{z \in C_{n-1}:\left\|z-T^{n} z\right\| \leq t_{n}\left\|x_{n}-T^{n} x_{n}\right\|\right\}
$$

denotes the convex closure of the set $\left\{z \in C_{n-1}:\left\|z-T^{n} z\right\| \leq t_{n}\left\|x_{n}-T^{n} x_{n}\right\|\right\}$ and $P_{C_{n}}$ is the metric projection from $E$ onto $C_{n}$. Then $\left\{x_{n}\right\}$ converges strongly to $P_{\mp} x$.

Proof. (I) First we prove that $\left\{x_{n}\right\}$ is well defined and bounded.

It is easy to check that $C_{n}$ is closed and convex and $\mathcal{F} \subset C_{n}$ for all $n \geq 0$. Therefore, $\left\{x_{n}\right\}$ is well defined.

Put $p=P_{\mp} x$. Since $\mathcal{F} \subset C_{n}$ and $x_{n+1}=P_{C_{n}} x$, we have that

$$
\left\|x_{n+1}-x\right\| \leq\|p-x\|
$$

for all $n \geq 0$. Hence, $\left\{x_{n}\right\}$ is bounded.

(II) Now we prove that $\left\|x_{n}-T^{n-k} x_{n}\right\| \rightarrow 0$ as $n \rightarrow \infty$ for any $k \in \mathbb{N}$ ( $\mathbb{N}$ denotes the set of all positive integers).

Fix $k \in \mathbb{N}$ and put $l=n-k, n>k$. Since $x_{n}=P_{C_{n-1}} x$, we have $x_{n} \in C_{n-1} \subset \cdots \subset C_{l}$. Then there exist some positive integer $m \in \mathbb{N},\left\{\mu_{i}\right\} \in \Delta^{m}$ and $\left\{z_{i}\right\}_{i=0}^{m}\left\{z_{i}\right\}_{i=1}^{m} \subset C_{l-1}$ such that

$$
\begin{gathered}
\left\|x_{n}-\sum_{j=0}^{m} \mu_{j} z_{j}\right\|<t_{l}, \\
\left\|z_{j}-T^{l} z_{j}\right\| \leq t_{l}\left\|x_{l}-T^{l} x_{l}\right\|,
\end{gathered}
$$

for all $j \in\{0,1, \ldots, m\}$. Take $\alpha \in(0,1) \cap\left(0, \lambda / K^{2}\right]$. Put $M=\sup _{x \in C}\|x\|, p=P_{\mp} x, r_{0}=$ $\sup _{n \geq 1}\left\|x_{n}-p\right\|$ and $\beta_{l, \alpha}=\sqrt{2 \alpha\left(k_{l}-1\right)+1}$. we define

$$
S_{n, \alpha} x=\frac{1}{\sqrt{2 \alpha\left(k_{n}-1\right)+1}}\left[(1-\alpha) x+\alpha T^{n} x\right]
$$

for all $x \in C$ and each $n \geq 1$, then $S_{l, \alpha} p=\left(1 / \beta_{l, \alpha}\right) p$. It follows from Lemma 3.1 and (3.5) that 
8

Abstract and Applied Analysis

$$
\begin{aligned}
& \left\|x_{l}-T^{l} x_{l}\right\|=\frac{\beta_{l, \alpha}}{\alpha}\left\|\frac{1}{\beta_{l, \alpha}}\left(\alpha T^{l} x_{l}+(1-\alpha) x_{l}\right)-\frac{1}{\beta_{l, \alpha}} x_{l}\right\| \\
& =\frac{\beta_{l, \alpha}}{\alpha}\left\|\left(S_{l, \alpha} x_{l}-S_{l, \alpha} p\right)+\frac{1}{\beta_{l, \alpha}}\left(p-x_{l}\right)\right\| \\
& \leq \frac{\beta_{l, \alpha}+1}{\alpha} r_{0}, \\
& \left\|T^{l}\left(\sum_{j=0}^{m} \mu_{j} z_{j}\right)-T^{l} x_{n}\right\| \\
& \quad \leq \frac{\beta_{l, \alpha}}{\alpha}\left(\left\|S_{l, \alpha}\left(\sum_{j=0}^{m} \mu_{j} z_{j}\right)-S_{l, \alpha} x_{n}\right\|+\frac{1-\alpha}{\beta_{l, \alpha}}\left\|\sum_{j=0}^{m} \mu_{j} z_{j}-x_{n}\right\|\right) \\
& \leq\left(\frac{\beta_{l, \alpha}+1}{\alpha}-1\right)\left\|\sum_{j=0}^{m} \mu_{j} z_{j}-x_{n}\right\| \\
& \leq\left(\frac{\beta_{l, \alpha}+1}{\alpha}-1\right) t_{l} .
\end{aligned}
$$

Moreover, from Lemmas 2.4 and 3.1, we have

$$
\begin{aligned}
& \left\|T^{l}\left(\sum_{j=0}^{m} \mu_{j} z_{j}\right)-\sum_{j=0}^{m} \mu_{j} T^{l} z_{j}\right\| \\
& \quad=\frac{\beta_{l, \alpha}}{\alpha}\left\|S_{l, \alpha}\left(\sum_{j=0}^{m} \mu_{j} z_{j}\right)-\sum_{j=0}^{m} \mu_{j} S_{l, \alpha} z_{j}\right\| \\
& \quad \leq \frac{\beta_{l, \alpha}}{\alpha} \gamma^{-1}\left[\max _{0 \leq j<k \leq m}\left(\left\|z_{j}-z_{k}\right\|-\left\|S_{l, \alpha} z_{j}-S_{l, \alpha} z_{k}\right\|\right)\right] \\
& \leq \frac{\beta_{l, \alpha}}{\alpha} r^{-1}\left[\max _{0 \leq j<k \leq m}\left(\left\|z_{j}-S_{l, \alpha} z_{j}\right\|+\left\|z_{k}-S_{l, \alpha} z_{k}\right\|\right)\right] \\
& \leq \frac{\beta_{l, \alpha}}{\alpha} r^{-1}\left\{\operatorname { m a x } _ { 0 \leq j < k \leq m } \left[\frac{\alpha}{\beta_{l, \alpha}}\left(\left\|z_{j}-T^{l} z_{j}\right\|+\left\|z_{k}-T^{l} z_{k}\right\|\right)\right.\right. \\
& \quad \leq \frac{\beta_{l, \alpha}}{\alpha} \gamma^{-1}\left\{\frac{2 \alpha t_{l}}{\beta_{l, \alpha}}\left\|x_{l}-T^{l} x_{l}\right\|+2\left(1-\frac{1}{\beta_{l, \alpha}}\right) M\right\} \\
& \quad \leq \frac{\beta_{l, \alpha}}{\alpha} \gamma^{-1}\left\{\frac{2 \alpha t_{l}}{\beta_{l, \alpha}}\left\{\frac{\beta_{l, \alpha}+1}{\alpha} r_{0}\right\}+2\left(1-\frac{1}{\beta_{l, \alpha}}\right) M\right\} \\
& \quad=\frac{\beta_{l, \alpha}}{\alpha} \gamma^{-1}\left\{2\left(1+\frac{1}{\beta_{l, \alpha}}\right) r_{0} t_{l}+2\left(1-\frac{1}{\beta_{l, \alpha}}\right) M\right\} .
\end{aligned}
$$


Observe that $\beta_{l, \alpha} \rightarrow 1$ as $n \rightarrow \infty$, it follows from (3.5)-(3.9) that

$$
\begin{aligned}
\left\|x_{n}-T^{l} x_{n}\right\| \leq & \left\|x_{n}-\sum_{j=0}^{m} \mu_{j} z_{j}\right\|+\left\|\sum_{j=0}^{m} \mu_{j}\left(z_{j}-T^{l} z_{j}\right)\right\| \\
& +\left\|\sum_{j=0}^{m} \mu_{j} T^{l} z_{j}-T^{l}\left(\sum_{j=0}^{m} \mu_{j} z_{j}\right)\right\|+\left\|T^{l}\left(\sum_{j=0}^{m} \mu_{j} z_{j}\right)-T^{l} x_{n}\right\| \\
\leq & t_{l}+t_{l}\left\|x_{l}-T^{l} x_{l}\right\|+\frac{\beta_{l, \alpha}}{\alpha} \gamma^{-1}\left\{2\left(1+\frac{1}{\beta_{l, \alpha}}\right) r_{0} t_{l}+2\left(1-\frac{1}{\beta_{l, \alpha}}\right) M\right\} \\
& +\left(\frac{\beta_{l, \alpha}+1}{\alpha}-1\right) t_{l} \\
\leq & t_{l}+\frac{\beta_{l, \alpha}+1}{\alpha} r_{0} t_{l}+\frac{\beta_{l, \alpha}}{\alpha} \gamma^{-1}\left\{2\left(1+\frac{1}{\beta_{l, \alpha}}\right) r_{0} t_{l}+2\left(1-\frac{1}{\beta_{l, \alpha}}\right) M\right\} \\
& +\left(\frac{\beta_{l, \alpha}+1}{\alpha}-1\right) t_{l} \longrightarrow 0 \text { as } n \longrightarrow \infty .
\end{aligned}
$$

This shows that

$$
\left\|x_{n}-T^{l} x_{n}\right\| \longrightarrow 0 \quad \text { as } n \longrightarrow \infty
$$

(III) we prove that $\left\|x_{n}-T x_{n}\right\| \rightarrow 0$ as $n \rightarrow \infty$.

Since $T$ is a uniformly $L$-Lipschitzian, we have

$$
\begin{aligned}
\left\|x_{n}-T x_{n}\right\| & \leq\left\|x_{n}-T^{n-1} x_{n}\right\|+\left\|T^{n-1} x_{n}-T x_{n}\right\| \\
& \leq\left\|x_{n}-T^{n-1} x_{n}\right\|+L\left\|T^{n-2} x_{n}-x_{n}\right\| \longrightarrow 0 \quad \text { as } \quad n \rightarrow \infty
\end{aligned}
$$

(IV) Finally, we prove that $x_{n} \rightarrow p=P_{\bar{q}} x$.

It follows from the boundedness of $\left\{x_{n}\right\}$ that for each subsequence $\left\{x_{n_{i}}\right\} \subset\left\{x_{n}\right\}$ there exists a subsequence (without loss of generality we can still denote it by) $\left\{x_{n_{i}}\right\}$ such that $x_{n_{i}} \rightarrow v$ as $i \rightarrow \infty$. Since $T: C \rightarrow C$ is a uniformly $L$-Lipschitzian and $\left(\lambda,\left\{k_{n}\right\}\right)$-strict asymptotically pseudocontraction, from Lemma 2.3, we know that $T$ is demiclosed. Hence we have $v \in \mathcal{F}$.

From the weakly lower semicontinuity of the norm and (3.4), it follows that

$$
\begin{aligned}
\|p-x\| & \leq\|v-x\| \leq \liminf _{i \rightarrow \infty}\left\|x_{n_{i}}-x\right\| \\
& \leq \limsup _{i \rightarrow \infty}\left\|x_{n_{i}}-x\right\| \leq\|p-x\| .
\end{aligned}
$$


This shows $p=v$ and hence $x_{n_{i}} \rightarrow p$ as $i \rightarrow \infty$. By the arbitrariness of $\left\{x_{n_{i}}\right\} \subset\left\{x_{n}\right\}$, we obtain $x_{n} \rightarrow p$. Further, it follows from (3.13) that

$$
\lim _{n \rightarrow \infty}\left\|x_{n}-x\right\|=\|p-x\|
$$

Since $E$ is uniformly convex, it has the Kadec-Klee property. Hence, we have $x_{n}-x \rightarrow p-x$, that is, $x_{n} \rightarrow p$. This completes the proof.

\section{Acknowledgment}

The authors would like to express their thanks to the referees for their helpful comments and suggestions. Supported by the Scientific Research Fund of Sichuan Provincial Education Department (11ZA221) and the Scientic Research Fund of Science Technology Department of Sichuan Province 2011JYZ010.

\section{References}

[1] F. E. Browder and W. V. Petryshyn, "Construction of fixed points of nonlinear mappings in Hilbert space," Journal of Mathematical Analysis and Applications, vol. 20, pp. 197-228, 1967.

[2] Q. Liu, "Convergence theorems of the sequence of iterates for asymptotically demicontractive and hemicontractive mappings," Nonlinear Analysis, vol. 26, no. 11, pp. 1835-1842, 1996.

[3] F. Gu, "The new composite implicit iterative process with errors for common fixed points of a finite family of strictly pseudocontractive mappings," Journal of Mathematical Analysis and Applications, vol. 329, no. 2, pp. 766-776, 2007.

[4] M. O. Osilike, "Implicit iteration process for common fixed points of a finite family of strictly pseudocontractive maps," Journal of Mathematical Analysis and Applications, vol. 294, no. 1, pp. 73-81, 2004.

[5] Y. Su and S. Li, "Composite implicit iteration process for common fixed points of a finite family of strictly pseudocontractive maps," Journal of Mathematical Analysis and Applications, vol. 320, no. 2, pp. 882-891, 2006.

[6] H.-K. Xu and R. G. Ori, "An implicit iteration process for nonexpansive mappings," Numerical Functional Analysis and Optimization, vol. 22, no. 5-6, pp. 767-773, 2001.

[7] Y. Su, M. Li, and H. Zhang, "New monotone hybrid algorithm for hemi-relatively nonexpansive mappings and maximal monotone operators," Applied Mathematics and Computation, vol. 217, no. 12, pp. 5458-5465, 2011.

[8] S. S. Chang, H. W. J. Lee, C. K. Chan, and J. K. Kim, "Approximating solutions of variational inequalities for asymptotically nonexpansive mappings," Applied Mathematics and Computation, vol. 212, no. 1, pp. 51-59, 2009.

[9] H. Zegeye and N. Shahzad, "Convergence of Mann's type iteration method for generalized asymptotically nonexpansive mappings," Computers \& Mathematics with Applications, vol. 62, no. 11, pp. 4007-4014, 2011.

[10] X. Qin, S. Huang, and T. Wang, "On the convergence of hybrid projection algorithms for asymptotically quasi- $\varphi$-nonexpansive mappings," Computers \& Mathematics with Applications, vol. 61, no. 4, pp. 851-859, 2011.

[11] S. S. Chang, L. Wang, Y.-K. Tang, B. Wang, and L.-J. Qin, "Strong convergence theorems for a countable family of quasi- $\varphi$-asymptotically nonexpansive nonself mappings," Applied Mathematics and Computation, vol. 218, no. 15, pp. 7864-7870, 2012.

[12] W. Nilsrakoo, "Halpern-type iterations for strongly relatively nonexpansive mappings in Banach spaces," Computers $\mathcal{E}$ Mathematics with Applications, vol. 62, no. 12, pp. 4656-4666, 2011.

[13] S. S. Chang, H. W. J. Lee, C. K. Chan, and J. ai Liu, "Strong convergence theorems for countable families of asymptotically relatively nonexpansive mappings with applications," Applied Mathematics and Computation, vol. 218, no. 7, pp. 3187-3198, 2011. 
[14] W. Nilsrakoo and S. Saejung, "Strong convergence theorems by Halpern-Mann iterations for relatively nonexpansive mappings in Banach spaces," Applied Mathematics and Computation, vol. 217, no. 14, pp. 6577-6586, 2011.

[15] S. Suantai, W. Cholamjiak, and P. Cholamjiak, "An implicit iteration process for solving a fixed point problem of a finite family of multi-valued mappings in Banach spaces," Applied Mathematics Letters, vol. 25, no. 11, pp. 1656-1660, 2012.

[16] S. S. Chang, K. K. Tan, H. W. J. Lee, and C. K. Chan, “On the convergence of implicit iteration process with error for a finite family of asymptotically nonexpansive mappings," Journal of Mathematical Analysis and Applications, vol. 313, no. 1, pp. 273-283, 2006.

[17] S. S. Chang, H. W. J. Lee, C. K. Chan, and W. B. Zhang, "A modified halpern-type iteration algorithm for totally quasi- $\varphi$-asymptotically nonexpansive mappings with applications," Applied Mathematics and Computation, vol. 218, no. 11, pp. 6489-6497, 2012.

[18] X. Qin, S. Y. Cho, and S. M. Kang, "Strong convergence of shrinking projection methods for quasi- $\varphi$ nonexpansive mappings and equilibrium problems," Journal of Computational and Applied Mathematics, vol. 234, no. 3, pp. 750-760, 2010.

[19] D. Wu, S. S. Chang, and G. X. Yuan, "Approximation of common fixed points for a family of finite nonexpansive mappings in Banach space," Nonlinear Analysis, vol. 63, no. 5-7, pp. 987-999, 2005.

[20] C. Zhang, J. Li, and B. Liu, "Strong convergence theorems for equilibrium problems and relatively nonexpansive mappings in Banach spaces," Computers \& Mathematics with Applications, vol. 61, no. 2, pp. 262-276, 2011.

[21] M. O. Osilike, A. Udomene, D. I. Igbokwe, and B. G. Akuchu, “Demiclosedness principle and convergence theorems for $k$-strictly asymptotically pseudocontractive maps," Journal of Mathematical Analysis and Applications, vol. 326, no. 2, pp. 1334-1345, 2007.

[22] K. Nakajo and W. Takahashi, "Strong convergence theorems for nonexpansive mappings and nonexpansive semigroups," Journal of Mathematical Analysis and Applications, vol. 279, no. 2, pp. 372 $379,2003$.

[23] H.-K. Xu, "Strong convergence of approximating fixed point sequences for nonexpansive mappings," Bulletin of the Australian Mathematical Society, vol. 74, no. 1, pp. 143-151, 2006.

[24] S.-Y. Matsushita and W. Takahashi, "Approximating fixed points of nonexpansive mappings in a Banach space by metric projections," Applied Mathematics and Computation, vol. 196, no. 1, pp. 422 425, 2008.

[25] H. Dehghan, "Approximating fixed points of asymptotically nonexpansive mappings in Banach spaces by metric projections," Applied Mathematics Letters, vol. 24, no. 9, pp. 1584-1587, 2011.

[26] S. M. Kang and S. Wang, "New hybrid algorithms for nonexpansive mappings in Banach spaces," International Journal of Mathematical Analysis, vol. 5, no. 9-12, pp. 433-440, 2011.

[27] Y. I. Alber, "Metric and generalized projection operators in Banach spaces: properties and applications," in Theory and Applications of Nonlinear Operators of Accretive and Monotone Type, vol. 178 of Lecture Notes in Pure and Applied Mathematics, pp. 15-50, Dekker, New York, NY, USA, 1996.

[28] W. Takahashi, Nonlinear Function Analysis. Fixed Points Theory and Its Applications, Yokohama Publishers, Yokohama, 2000.

[29] F. E. Browder, "Convergence theorems for sequences of nonlinear operators in Banach spaces," Mathematische Zeitschrift, vol. 100, pp. 201-225, 1967.

[30] D. Pascali and S. Sburlan, Nonlinear Mappings of Monotone Type, Noordhoff, Leyden, Mass, USA, 1978.

[31] M. O. Osilike, S. C. Aniagbosor, and B. G. Akuchu, "Fixed points of asymptotically demicontractive mappings in arbitrary Banach spaces," Panamerican Mathematical Journal, vol. 12, no. 2, pp. 77-88, 2002.

[32] H. K. Xu, "Inequalities in Banach spaces with applications," Nonlinear Analysis, vol. 16, no. 12, pp. 1127-1138, 1991.

[33] R. E. Bruck, "On the convex approximation property and the asymptotic behavior of nonlinear contractions in Banach spaces," Israel Journal of Mathematics, vol. 38, no. 4, pp. 304-314, 1981. 


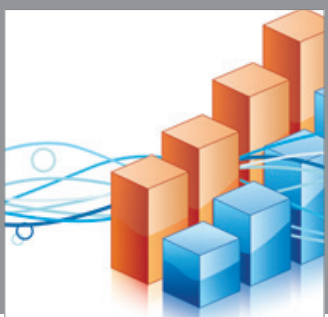

Advances in

Operations Research

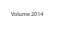

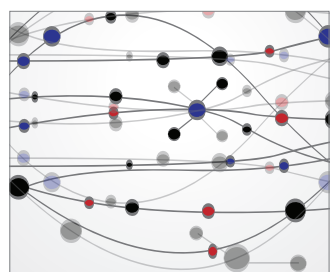

\section{The Scientific} World Journal
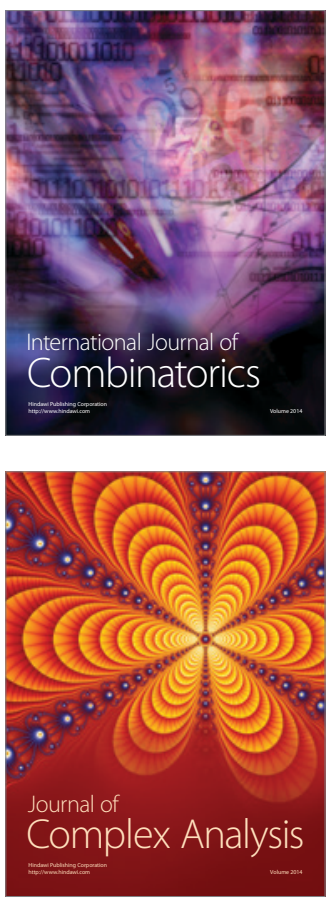

International Journal of

Mathematics and

Mathematical

Sciences
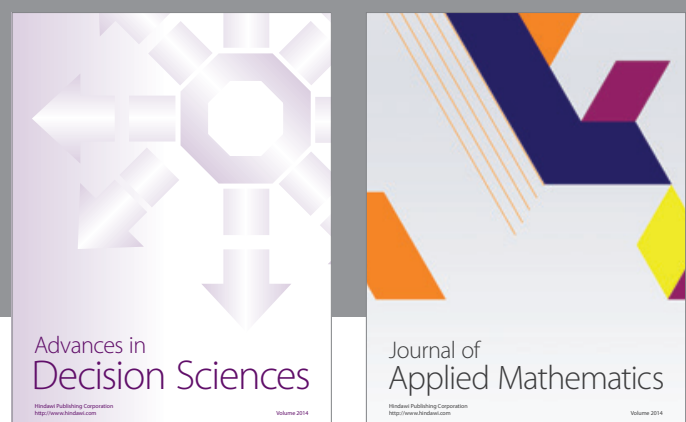

Journal of

Applied Mathematics
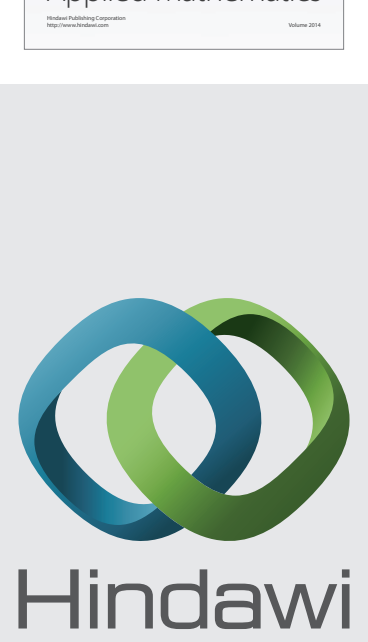

Submit your manuscripts at http://www.hindawi.com
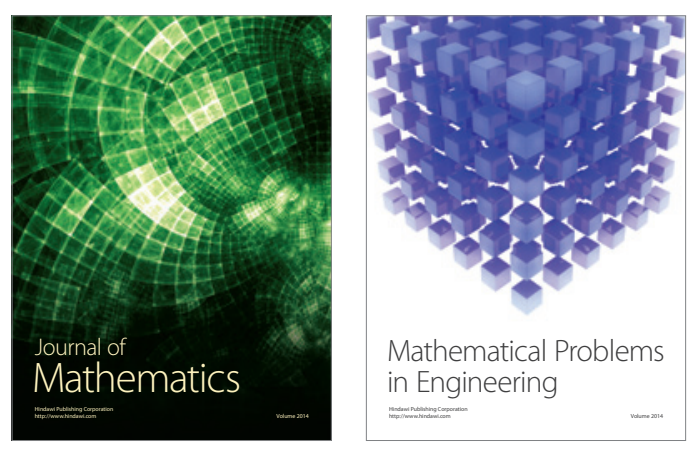

Mathematical Problems in Engineering
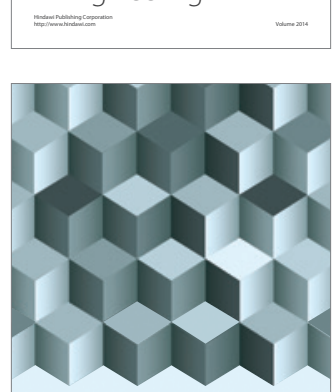

Journal of

Function Spaces
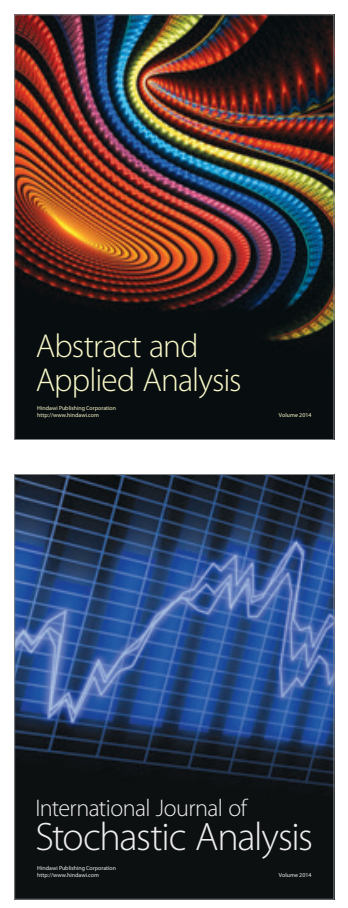

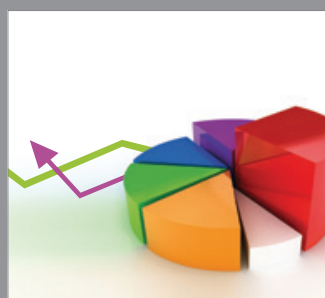

ournal of

Probability and Statistics

Promensencen
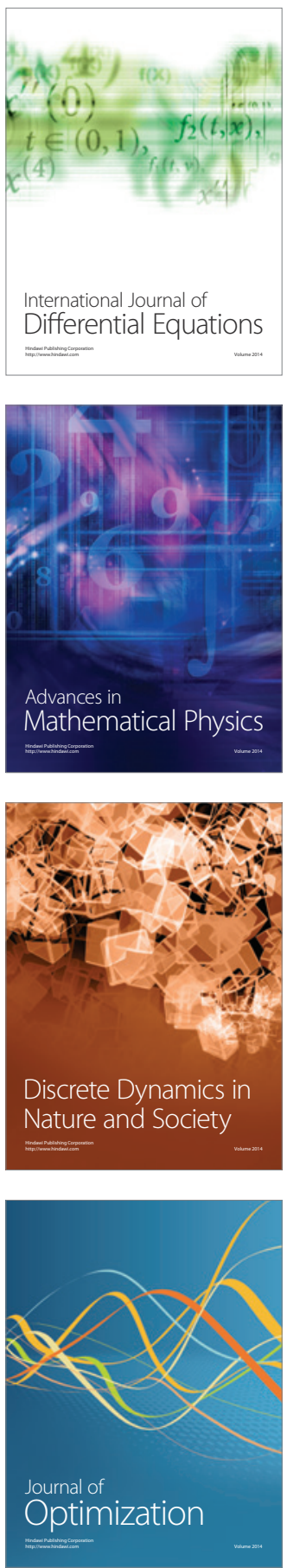